Article

\title{
Inclusive Nature-Based Solutions for Urban Regeneration in a Natural Disaster Vulnerability Context: A Case Study of Chongqing, China
}

\author{
Pengcheng Xiang *, Yiming Wang and Qing Deng \\ School of Construction Management and Real Estate, Chongqing University, Chongqing 400044, China; \\ yimingwang@cqu.edu.cn (Y.W.); qingdeng@cqu.edu.cn (Q.D.) \\ * Correspondence: pcxiang@cqu.edu.cn; Tel.: +86-23-6512-0848 \\ Academic Editor: Tan Yigitcanlar \\ Received: 31 May 2017; Accepted: 4 July 2017; Published: 10 July 2017
}

\begin{abstract}
Currently, economic development has become a dominant factor in the promotion of urban regeneration in China. This means that decision makers often overlook the impacts on the natural environment when planning urban regeneration within a region. To properly face such challenges and others that may arise, a strategy relying on Nature-Based Solutions (NBS) can enhance the physical and ecological environment of a city, while ensuring greater resilience to natural disasters, and the use of fewer resources. NBS also improves the social well-being of citizens by creating more inclusive and engaged communities. This paper reviews the literature concerning urban regeneration and natural disaster vulnerability to discuss the complex mechanisms of the interactions between natural disaster and urban regeneration. Then, the evaluation model of natural disaster vulnerability in urban area is constructed, and data envelopment analysis (DEA) model is used to assess the vulnerability of natural disasters in various regions of Chongqing. Finally, under the background of NBS, this paper puts forward the way of urban regeneration, and provides an important direction for urban regeneration to realize the sustainable development of cities.
\end{abstract}

Keywords: urban regeneration; nature-based solutions; natural disaster; vulnerability; DEA model

\section{Introduction}

Mass urbanization presents one of the most urgent challenges of the 21st century. Rapidly developing and changing industrial activities and uncontrolled urban sprawl, as well as large, concentrated and often culturally diverse populations have created numerous complex social and health problems [1]. The challenges that cities and urban communities have to cope with are numerous, including poor air quality, heat island effects, increased frequency and severity of extreme events such as floods, droughts, storms and heat waves, derelict industrial sites, dis-functioning urban areas, increased criminality, social exclusion, inequalities, marginalization, poverty and degraded urban environments [2-4]. These challenges have serious impacts on human health, quality of life, well-being and the security of citizens, particularly among the less privileged social classes. At present, China is one of the fastest growing economies in the world, and sustained economic growth has contributed to the process of urban regeneration $[5,6]$. This involves the development of the city's new area for expansion, and the redevelopment of previously used areas with large-scale demolition and reconstruction in order to make full use of scarce land in the urban centers under the influence of economic development $[7,8]$.

However, from a sustainable development perspective, large-scale demolition and construction in the city is an unsustainable development path. In her book "The Death and Life of Great American Cities", Jane Jacobs points out that "Large-scale projects can only benefit architects, politicians 
and real estate developers, but the masses always become victims" [9]. The degree to which a region is vulnerable to natural disaster can be obtained through a calculation of the comprehensive disaster efficiency and regional map of natural disaster risk [10]. This not only affects the healthy development of a city, but is also related to the stability of society as a whole. Urban regeneration is an economic activity, which can promote China's modernization and urbanization, but it is also related to social behaviors. From the perspective of natural disasters, urban regeneration requires the attention of all sectors of society. Urban regeneration is not only a matter of improving the physical environment, but also creates a profound social change that involves the spatial structure of a city. Inappropriate guidance could be counterproductive and lead to a greater social crisis. Therefore, how to effectively carry out urban regeneration in areas at risk of natural disasters has become the main problem of urban construction.

There is convincing but fragmented evidence that nature-based solutions (NBS) can significantly enhance the natural disasters resilience of cities. Furthermore nature-based solutions, by reshaping the built environment, can enhance the inclusivity, equitability and livability of the cities, regenerate deprived districts, improve mental and physical health and quality of life for the citizens, reduce urban violence, and decrease social tensions through better social cohesion particularly for the most vulnerable groups, e.g., children, elderly and people of low socioeconomic status.

The challenge is therefore to provide a robust, China-wide evidence base and develop a China reference framework on nature-based solutions for regional and local city authorities, communities, enterprises and other stakeholders about the benefits, co-benefits, cost-effectiveness and economic viability of these solutions to enhance on the one hand natural disasters resilience in cities and on the other hand to address inclusive urban regeneration in cities and thus promote their large scale deployment and the creation of a global market.

However existing experiments and innovation actions were focused on single NBS, or on small-scale testing in different contexts. This trend has been seen in past or ongoing EU-funded projects (e.g., Blue-Green Dreams, and Opera6). Only recently some cities in Europe and beyond (see, for instance, the Oppla case-studies, or London green-roofs plan) started to experiment upscaling of NBS [11]. This "new generation" of NBS demonstrators are conceived and focused on the environmental scope of NBS, while their social dimension, when present, is just a by-product of an improved urban environment. The urban landscape has an immense potential when considering the importance of the relationship between NBS and the city itself, intended as an active and dynamic society [12,13].

In order to provide a research context, the key issue examined in the literature review is urban regeneration in the context of natural disaster vulnerability. Subsequently, taking account of the interaction between urban regeneration and natural disasters, the mechanism of urban regeneration and natural disaster is studied. Then, through a data envelopment analysis (DEA) model, which assesses the vulnerability to natural disasters in various urban regions, Chongqing is selected as the case for empirical analysis. Finally, urban regeneration strategies that rely on Nature-Based Solutions are put forward.

\section{Literature Review}

\subsection{The Concept of Urban Regeneration}

Due to the decline of cities and the deterioration of buildings around the world, urban regeneration has received great attention from researchers [14]. The term "urban regeneration", which is usually interchangeable with "urban redevelopment", "urban rehabilitation", and "urban revitalization", is a process that involves the rehabilitation of existing structures, redevelopment of buildings, or reuse of urban land [15]. Urban regeneration is a complex process involving the modernization and reconstruction to improve the deterioration of buildings or communities [16,17]. Chen defines urban regeneration as a process of "metabolism" [18]. Wu puts forward the concept of "organic regeneration" 
from the point of "protection and development", and emphasizes the city's material environment, while ignoring social and cultural factors [19]. With the rapid development of urbanization, has been an increase in urban problems, so corresponding urban policies should be formulated to solve them $[3,4]$. The purpose of regeneration is to increase the competitiveness of the city as a whole [6] and to consider the overall development of city from economic, social and environmental aspects, so as to improve the urban structure [20]. Zhang proposed to not only improve the material environment, but also to consider the improvement of its non-material environment, such as neighborhood social network structure, psychological setting and emotional attachments [21]. Roberts defines urban regeneration as an integrated, holistic approach to solving a wide range of urban problems [22]. Hausner suggests that the process of urban regeneration should not only broaden horizons, but also reflect the characteristics and needs of specific cities or sections [23]. These different expressions show scholars' focuses and understandings of urban regeneration from different perspectives. Based on the definition by scholars from home and abroad, urban regeneration is necessary and planned renovation and reconstruction of areas which cannot adapt to the sustainable development of the modern city. In summary, urban regeneration aims at improving the physical, social-economic and ecological aspects of urban areas through various actions including redevelopment, rehabilitation, and revitalization. In these respects, urban regeneration can significantly contribute to inclusive urban development [14,15].

\subsection{The Concept of Natural Disaster Vulnerability}

Research at the Centre for International Earth Science Information Network (CIESIN) shows that 900 million people in 450 of the world's 633 megacities are exposed to at least one disaster risk [24]. When the risk occurs, social and economic losses also tend to increase with the size of a city's expansion. In view of this, scholars have also given great attention to natural disasters. In the field of disaster research, the concept of vulnerability is diverse. The International Strategy for Disaster Reduction (ISDR) considers that vulnerability is a reflection of the ability to withstand disasters, which is determined by nature, society, economy and the environment [25]. Considering the purpose of vulnerability research is ultimately to aid decision-making, Cannon argues that vulnerability is a greater predictor than terms showing present situation, such as poverty, and it is an explanation of the consequences for specific groups of people under specific hazards and conditions of risk [26]. Vulnerability is the internal and dynamic characteristics of the risk recipient (community, region, country, infrastructure, environment, etc.) and determines the expected loss under specific disasters [27]. Vulnerability is determined by nature, society, economy and environment and changes over time. This shows that different research areas have differing focuses on vulnerability. Among these, natural science focuses on the consequences of the individual or the system, while social science focuses on factors from the society, economy and other aspects that cause the vulnerabilities. Crichton points out that the relationship between risk and vulnerability is "risk $=$ hazard $\times$ exposure $\times$ vulnerability" [28]. Shi believes that disasters are composed of four parts: disaster-causing factors, disaster inducing environment, disaster-bearing body and conditions of disaster [29].

In summary, vulnerability of natural disasters should be understood in two dimensions: whether the disaster-bearing body is the system or individual, and the other is whether the origin of the fragility is analyzed from physical attributes of the disaster-bearing body or from the social point of view.

\subsection{NBS for Inclusive Urban Regeneration}

The urban landscape has immense potential where the relationship between Nature-Based Solutions (NBS) and the city itself (as an active and dynamic society and all that entails), pose an important role. The novelty will stand on clustering NBS in an inclusive environment through the empowerment, capacitation and integration in the community [30]. There is a strong intention to reconnect fragmented areas enhancing the natural capital in favor of the communities, as promoted by the European Union. Innovative NBS pilots have created urban farms and regenerated urban streams and green areas (working as blue and green networks) in the cities with high social benefits such 
as urban farms with ponds, rain-gardens, green-roofs based on cork material and vertical farming systems, and the use and connection of natural waterbodies as systems for water pollutants removal. Five types of NBS will be implemented: (i) create/reinforce social ties around NBS and neighborhood life through the participation in the NBS life-cycle, resulting in local associative networks organized in a permanent NBS committee; (ii) use of NBS to professionally train and capacitate local citizens, associations and SMEs for NBS replication and job opportunities; (iii) use of NBS to raise awareness on the urban environment dynamics through structured educational programs in partnership with local schools and associations; (iv) "Communiversity" creation; and (v) circular economy promotion among larger social classes [31].

The potential of NBS is twofold: NBS enhance the physical and ecological environment of a city, making it more resilient to water issues and climate change, more sustainable and less resource-consuming, but they also improve the social well-being of citizens, creating more inclusive and engaged communities [12]. The social benefits of NBS have been highlighted in recent years in different contexts, but they have not yet been systematically tested and demonstrated at the city-scale. Moreover, robust methods and solutions to promote and enhance the social role of NBS are lacking, and cities willing to improve their livability through NBS can only proceed by trial-and-error, with little or no guidance.

NBS can be the catalyst of neighborhood life and foster the creation of new social ties. By supporting, reinforcing and upscaling this function, NBS can simultaneously contribute to a healthier urban environment and a stronger, more inclusive society [31]. The core of NBS is to regenerate both the natural and social environments of deprived neighborhoods [30]. The extensive, large-scale test of NBS will result in a set of well-documented, robust and transferable solutions that any city, in China and beyond, will be able to apply to improve its inclusiveness, security and livability.

\section{Analysis on the Mechanism of Natural Disaster and Urban Renewal}

\subsection{The Impact of Urban Regeneration on Natural Disasters}

Urban regeneration involves a complicated change of spatial forms and the process of social and economic development [6]. It is common to have problems such as over-exploration of underground water, natural vegetation degradation, low vegetation coverage and water pollution in urban areas. The urban regeneration process in most developing countries is too fast, and the urban population is expanding, causing serious environmental problems.

\subsubsection{Easy to Induce a Variety of Natural Disasters}

At present, most of China's urban regeneration adopts the large-scale "demolition" and "relocation" model, which seriously erodes urban green spaces. Maintaining the balance of ecosystems is an important factor in protecting the natural environment, and the destruction of the urban green space system increases the probability of potential natural disasters.

\subsubsection{Natural Disasters Occur More Frequently}

Urban regeneration increases the intensity, frequency, area and time occurrence of natural disasters. The construction of engineering and renovation activities as part of urban regeneration caused disturbance of the ecological environment which leads to land degradation in the regeneration area. For areas where frequent flooding occurs, such as Chongqing, the acceleration of urban regeneration has increased the area of impervious hard ground, and the rainwater infiltration channel has been blocked, leading to an increase in flood intensity.

\subsection{The Impact of Urban Regeneration on Natural Disasters}

Natural disasters are natural events that occur in certain natural environments. They cause the loss of life and property by interacting with nature and human socio-economic systems and are 
beyond human control. Compared to other regions, the population and asset of the city is more concentrated, which places the population at greater risk of natural disasters. Natural disasters affect social productive capacity and cause the reduction of social wealth, which ultimately restricts the long-term economic development of a society. The impact of natural disasters may vary with the size of the population, the extent of scientific and technological advancement, the level of development of the society and the extent that human beings take advantage of the natural resources. Natural disasters limit the economic development of the affected areas and widened the economic gap between regions. The greater the economic gap, the greater impact it has on social stability. This is a vicious circle whereby the ecological environment becomes more fragile and the affected areas are made poorer. Therefore, impact of natural disasters is multifaceted and their occurrence undermines the harmonious conditions between human existence and development.

\subsubsection{Natural Disasters Increase the Difficulty of Urban Regeneration}

The high intensity of urban capital means that the city's comprehensive disaster tolerance is weakened, and city processes are destroyed, including transportation, power supply, water supply, communications, financial information networks and other infrastructure, which increases the difficulty of urban regeneration. In addition, natural disasters have a long-term negative impact on regional economic development by slowing down economic growth and causing imbalances in regions' economic development, making the smooth process of urban regeneration difficult.

\subsubsection{Natural Disasters Have Delayed the Process of Urban Regeneration}

Natural disasters delay the process of urban regeneration. The health of natural resources of a region are important for urban regeneration, and the destruction of these resources from natural disasters leads to a slowing down or complete stop in regional economic development. Further, natural disasters endanger human life and disrupt the normal life order of communities. Therefore, urban regeneration is impacted twofold, by the huge depletion of resources and degradation of the environment, and also by the diminished capacity for people to participate.

\section{Evaluation Model of Natural Disaster Vulnerability in Urban Area}

A disaster risk assessment is a quantitative analysis and assessment of the potential consequences of disaster risk areas at different intensities. This paper uses DEA model to evaluate the vulnerability of natural disasters because the conventional system of natural disaster vulnerability is too large and the disaster types too complex to consider. Based on the analysis of the DEA model to natural disaster vulnerability assessment, the vulnerability evaluation index system of regional disaster is constructed and the regional fragility level of natural disasters in the main urban area of Chongqing is quantitatively studied in order to provide scientific reference for the formulation and adjustment of regional disaster mitigation policies.

\subsection{Study Area}

Chongqing is China's most famous "mountain city" for its majestic natural features and geography. This provides a good case for studying urban regeneration in the context of natural disasters. Located in the upper reaches of the Yangtze River, Chongqing is a place where four parallel north-south mountains, namely, Jinyun, Zhongliang, Tongluo, and Mingyue intersect with the Jialing and Yangtze Rivers (Figure 1). The city built steep hills to protect the vast land that was previously flooded at the river interchange. Nearly half of the metropolitan area is located on slopes of greater than $25 \%$. In 1997, Chongqing became a direct-controlled municipality when the city underwent rapid change. Chongqing's metropolitan population increased from 2.89 million in 1994 to 7.1 million in 2013 and is expected to reach 12 million by 2020 [32]. Chongqing metropolitan area has expanded four times in just 15 years, from 158 square kilometers in 1996 to 650 square kilometers in 2011 [32] Chongqing has experienced and continues to undergo a process of urban regeneration over the past 20 years. 
The metropolitan area of Chongqing, including the districts of Yuzhong, Jiangbei, Nan'an, Jiulongpo, Shapingba, Dadukou, Beibei, Yubei and Banan, were selected for analysis due to the availability of data.
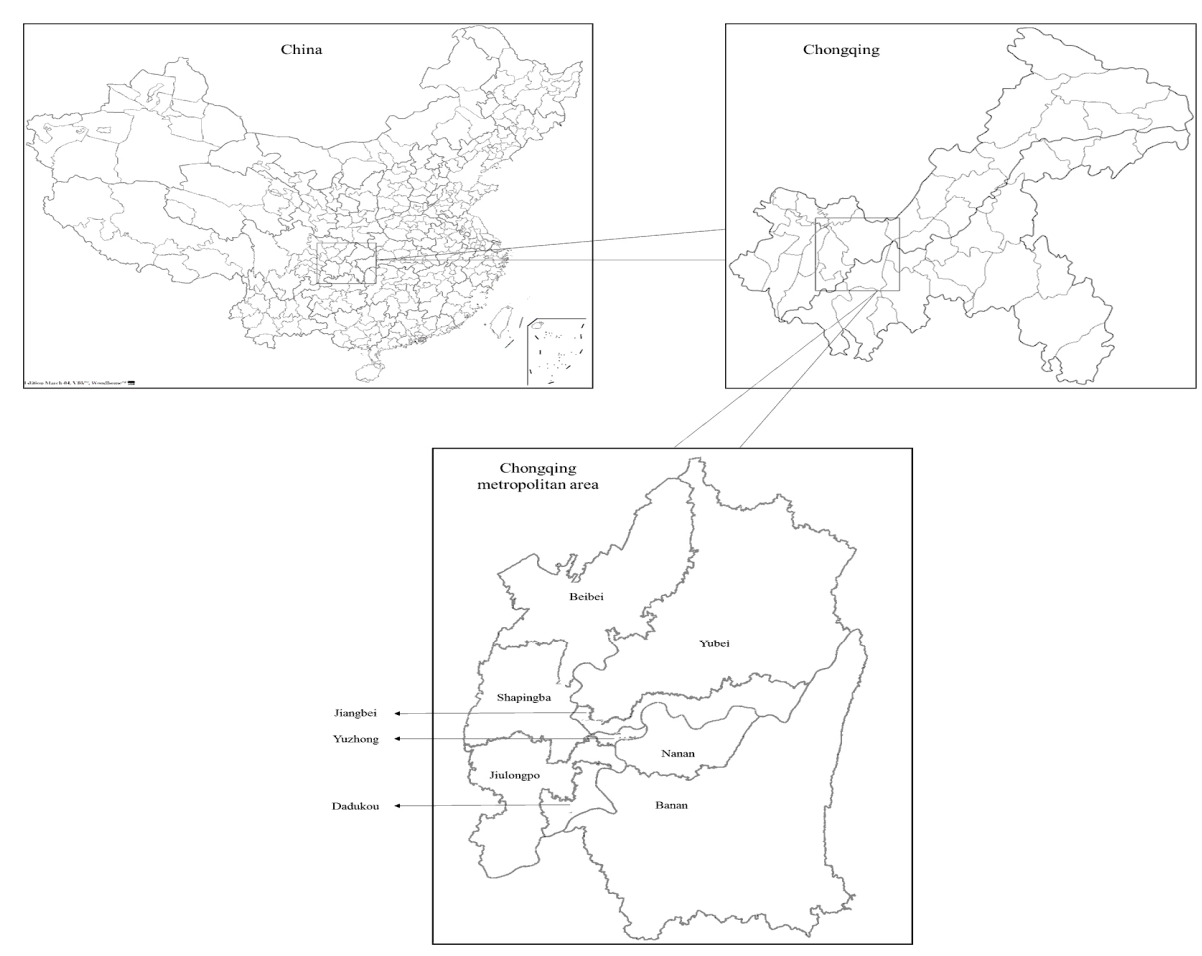

Figure 1. Location of Chongqing metropolitan area.

\subsection{Data Envelopment Analysis}

Data envelopment analysis (DEA) is a well-known method to sort the performance of decision-making units (DMU) with multiple inputs and outputs. This method was created by Charnes, Cooper, and Rhodes (1978), and maximizes the ratio of the weighted sum of outputs to the weighted sum of inputs for a DMU, subject to the condition that the same ratio for all DMUs must be less than or equal to one [33]. In this paper, the classical CCR model of DEA is used. This involves decision-making units (DMUj) $(j=1,2, \ldots, n)$, where each DMUj has the same $m$ inputs and outputs. The input vector is $X_{j}=\left(X_{1 j}, X_{2 j}, \ldots, X_{m j}\right)^{T}$, the output vector is $Y_{j}=\left(Y_{1 j}, Y_{2 j}, \ldots, Y_{m j}\right)^{T}$, and the CCR dual input model for regional natural disasters vulnerability assessment is as follows:

$$
\text { s.t }\left\{\begin{array}{c}
{\left[\theta-\varepsilon\left(e^{T} S^{-}+e^{T} S^{+}\right)\right]} \\
\sum_{j=1}^{n} X_{j} \lambda_{j}+S^{-}=\theta X_{0} \\
\sum_{j=1}^{n} X_{j} \lambda_{j}-S^{+}=Y_{0} \\
\lambda_{j} \geq 0, X_{J} \geq 0, Y_{J} \geq 0, j=1,2 \ldots, n \\
e^{T}=(1,1, \ldots, 1) \in E_{m}, e^{T}=(1,1, \ldots, 1) \in E_{n}
\end{array}\right.
$$

where $\theta(0<\theta \leq 1)$ is the comprehensive technical efficiency index of the DEA model; $\lambda$ is the weight change quantity; $S^{-}$is the relaxation variable; $S^{+}$is the residual variable; and $\varepsilon$ is the non-Archimedes Infinitesimal amount, generally taken as $\varepsilon=10^{-6}$. According to the meaning of DEA model, the closer the value of $\theta$, a regional evaluation unit, is to 1 , the higher the input-output ratio of the decision-making unit will be, and the higher the production efficiency level of the unit will be. 
Under the analysis of the input-output of the natural disaster system, it can be considered that the disaster efficiency of the evaluation unit is higher, which means the region is highly vulnerable, otherwise it is a low level vulnerable area. When $\theta=1$, it indicates that the input-output operation level of this region is on the optimal production frontier, and the output of the region has the optimal comprehensive efficiency compared to the input. This equates to the damage effect of the region under natural disasters reaching its maximum, and where the regional vulnerability level under natural disasters is the highest $[33,34]$.

\subsection{The Selection of Indicators and Data Processing}

The occurrence of natural disasters is the result of the synergistic effect of regional natural disaster system elements, including disaster-inducing factors, the exposure of regional resources and property, the ability of coordinating and adapting of disaster-affected bodies and the sensitivity of regional resources and property. However, each factor has different effects on the occurrence of disasters. Disaster-inducing factors have natural attributes and are inevitable. For the exposure of regional resources and property, the ability to coordinate and adapt the hazard-affected body and the sensitivity of regional resources and property, human factors play an important role. If the same kind of disaster occurs in different regional bodies with the same intensity, it will cause different results. The balance between the human and social environment can affect the seriousness of the disaster. This unbalanced situation can be improved through planning and management of human activities, thus showing that the vulnerability of a hazard-affected body is relative and can change with human activities. Therefore, the occurrence of the disaster is caused by the disaster-inducing factors, the exposure of vulnerable property of the regional hazard-affected body, the coordination of the regional disaster-bearing capacity and regional resources and property sensitivity. This paper will calculate the regional vulnerability level by using three aspects of regional disaster risk, the regional exposure level and regional disaster comprehensive loss as input-output factors of the DEA model. According to Regional Atlas of Chinese Typical Counties (Cities) Prone to Geological Disasters - Southwest Volume and China Statistical Yearbook, the input and output factors of the model evaluation indicators are selected as Table 1, taking Chongqing metropolitan area as the basic evaluation unit.

Table 1. The Selection and Procession of Indicators for Vulnerability Assessment.

\begin{tabular}{|c|c|c|c|}
\hline & Regional Disaster Risk Index & $\begin{array}{l}\text { Exposure Level of Regional } \\
\text { Hazard-Bearing Body }\end{array}$ & $\begin{array}{c}\text { Regional Disaster } \\
\text { Comprehensive Loss Degree }\end{array}$ \\
\hline $\begin{array}{l}\text { Indicator } \\
\text { Meaning }\end{array}$ & $\begin{array}{l}\text { Determined by } \\
\text { disaster-inducing factors and } \\
\text { vulnerability of regional } \\
\text { hazard-bearing body. }\end{array}$ & $\begin{array}{l}\text { It means vulnerable resources } \\
\text { and property exposed to natural } \\
\text { disasters, such as population, } \\
\text { houses, land and roads. The } \\
\text { more exposed they are, the more } \\
\text { potential losses there will be. }\end{array}$ & $\begin{array}{l}\text { Loss assessment after the } \\
\text { natural disaster, such as } \\
\text { casualties, the number of } \\
\text { collapsed houses and direct } \\
\text { economic losses. }\end{array}$ \\
\hline Index selection & $\begin{array}{l}\text { Mountain disaster (landslide, } \\
\text { collapse, debris flow), drought, } \\
\text { rainstorm flood }\end{array}$ & $\begin{array}{l}\text { Regional total population, GDP, } \\
\text { GDP per capita, population } \\
\text { density, regional urbanization } \\
\text { level }\end{array}$ & $\begin{array}{l}\text { Disaster area, died-out areas, } \\
\text { the total population affected, } \\
\text { the number of deaths due to the } \\
\text { disaster, the number of } \\
\text { collapsed houses, direct } \\
\text { economic losses }\end{array}$ \\
\hline $\begin{array}{l}\text { Data Processing } \\
\text { Method }\end{array}$ & $\begin{array}{l}\text { The mean-weighted } \\
\text { summation is used as input to } \\
\text { the DEA model. }\end{array}$ & $\begin{array}{l}\text { Factor analysis method is used } \\
\text { to extract the principal } \\
\text { component factors as input } \\
\text { factors of the DEA model. }\end{array}$ & $\begin{array}{l}\text { Factor analysis method is used } \\
\text { to extract the principal } \\
\text { component factors as the output } \\
\text { factor of DEA model. }\end{array}$ \\
\hline Data Sources & References $^{1}$ & $\begin{array}{l}\text { China Statistical Yearbook } \\
\text { 2011 2016 }\end{array}$ & $\begin{array}{l}\text { Statistical Yearbook of China's Civil } \\
\text { Administration 2011 2016 }\end{array}$ \\
\hline
\end{tabular}

${ }^{1}$ References include Chen et al., 1979 [18]; Yan et al., 2010 [35]; Global Facility for Disaster Reduction and Recovery (GFDRR), 2010 [36]; Zhang et al., 2013 [37]; Zhou et al., 2015 [38].

Some research experts have selected the evaluation index from the three aspects: disaster-inducing environment, natural disaster-inducing factors and disaster bearing bodies, according to the theory of 
natural disaster system and they produced the Chongqing hazard-inducing environment sensitivity map, the risk of natural disaster-inducing factors map, and the vulnerability map of the regional hazard-bearing body using GIS analysis. This paper analyzes the regional disparity of natural disasters in Chongqing, and carries out comprehensive regionalization of natural disasters to create four natural disaster areas. Based on the principle of the above-mentioned zoning, the metropolitan areas of Chongqing are selected as the study area, and the disaster risk index is calculated by assigning 1 to 5 as the regional hazard coefficient. Due to the stochastic nature of natural disasters, the inter-annual fluctuation of the statistical indicators of disaster losses is large, and it is not easy to use the data of disaster damage at a certain point of time to compare the regional vulnerability levels. However, for a certain period of time, the mean of natural disaster losses shows a certain stability, so it can be used to compare levels of regional damage losses. In order to maintain the consistency of input and output indicators, regional exposure indicators will also use the average for five years.

Using SPSS to analyze principal components of the original data of natural disaster exposure data and disaster damage degree, we can extract two principal components. According to the load distribution, it is clear that principal components of regional exposure show characteristics of density exposure and total exposure, while principal components of regional disaster damage depict regional losses through population property losses and agricultural losses. The score of factors obtained from principal components analysis and reduction of original variables may be negative, while the output value of the DEA model cannot be negative, so the data should be conversed [39]. The original data series is linearly transformed to a new data interval $[1,5]$ by using the min-max normalization method, and a new data series is formed. The formula is:

$$
V^{*}=\frac{V-\min _{A}}{\max _{A}-\min _{A}}\left(n e w_{-} \max _{A}-n e w_{-} \min _{A}\right)+n e w_{-} \min _{A}
$$

Based on the Chongqing Statistical Yearbook, the government work report and the statistics of environmental emergencies in Chongqing, this paper selects the data of the natural disasters in the nine districts of the urban area of Chongqing in a recent five-year time series [40]. Then, the relevant data of natural disasters input index and output indexes in the metropolitan areas of Chongqing are entered into the CCR model. Deap2.1 software is used to calculate natural disasters vulnerability in the nine districts of Chongqing (Table 2), to create more specific urban regeneration planning for these areas.

Table 2. The Vulnerability Assessment for Regional Natural Disasters of Chongqing.

\begin{tabular}{|c|c|c|c|c|c|c|}
\hline \multirow{2}{*}{$\begin{array}{l}\text { District of } \\
\text { Chongqing }\end{array}$} & \multicolumn{2}{|c|}{ Regional Exposure Level } & \multirow{2}{*}{$\begin{array}{c}\text { Regional Disaster } \\
\text { Risk }\end{array}$} & \multicolumn{2}{|c|}{ Regional Disaster Damage Degree } & \multirow{2}{*}{$\begin{array}{l}\text { Disaster Efficiency } \\
\text { (Vulnerability) }\end{array}$} \\
\hline & $\begin{array}{c}\text { Density } \\
\text { Exposure }\end{array}$ & $\begin{array}{c}\text { Total } \\
\text { Exposure }\end{array}$ & & $\begin{array}{c}\text { Population } \\
\text { Property Losses }\end{array}$ & $\begin{array}{l}\text { Agricultural } \\
\text { Losses }\end{array}$ & \\
\hline Yuzhong District & 1.48 & 1.95 & 3.00 & 3.47 & 2.32 & 1.000 \\
\hline Yubei District & 3.07 & 1.64 & 3.60 & 1.25 & 1.22 & 0.499 \\
\hline Jiangbei District & 2.79 & 1.40 & 3.40 & 1.17 & 1.55 & 0.639 \\
\hline Shapingba District & 1.49 & 3.75 & 3.80 & 2.28 & 3.45 & 0.719 \\
\hline Jiulongpo District & 1.36 & 2.29 & 3.40 & 2.29 & 3.18 & 0.853 \\
\hline Dadukou District & 1.32 & 2.47 & 2.20 & 1.56 & 1.78 & 0.678 \\
\hline Nan'an District & 3.27 & 2.08 & 3.58 & 3.21 & 2.39 & 0.926 \\
\hline Beibei District & 3.03 & 1.47 & 3.72 & 2.03 & 3.67 & 0.861 \\
\hline Banan District & 2.90 & 2.80 & 3.67 & 2.71 & 2.98 & 0.907 \\
\hline
\end{tabular}

\section{Discussion}

As can be seen in Table 2, in general, the natural disaster vulnerability level of Chongqing metropolitan area is high with the average disaster efficiency of 0.786 . The Yuzhong district is the most vulnerable to natural disasters with a vulnerability value of 1 ; with vulnerability values between 0.8 and 1 are the districts of Nanan, Banan, Beibei and Jiulongpo; the vulnerability to natural disasters in Shapingba, Dadukou and Jiangbei districts are at an average level with vulnerability values between 0.6 and 0.8 ; and the vulnerability of Yubei district is the lowest, with a vulnerability value of only 0.499 . 
The vulnerability to natural disasters natural disaster in the nine districts of Chongqing metropolitan area not the same, and there is a certain gap between them in terms of the level of vulnerability. This is related to the regional differentiation characteristics of the Chongqing natural disaster system. According to the input and output factors of the DEA model, the pattern of the natural disaster system in Chongqing is also consistent with the above analysis.

The most vulnerable districts of Yuzhong, Nanant, Banan, Beibei and Jiulongpo are all urban areas with high regional disaster damage, which is consistent with the geographical distribution of the natural disasters. The low vulnerability to regional natural disasters for the districts of Yubei, Jiangbei, Dadukou and Shapingba is obvious from the point of view of the regional natural disaster input-output system, where the four regions have obvious high input and low output characteristics (disaster risk and social and economic exposure are higher, and the degree of disaster loss is lower). This is due to the regional natural environment being less conducive to natural disasters and stronger disaster prevention and resilience, thus reducing vulnerability to regional natural disasters. According to the natural disaster efficiency of each city, combined with the relative efficiency value of the DEA model, the vulnerability level of natural disasters in Chongqing metropolitan area is divided into mild vulnerability (disaster efficiency $\theta<0.6$ ), moderate vulnerability $(0.6 \leq \theta<0.8)$, highly fragile high vulnerability $(0.8 \leq \theta<1.0)$, and highly fragile severe vulnerability $(\theta=1)$, as shown in Figure 2 .

It can be seen from Figure 2 that the areas with low vulnerability to natural disasters in Chongqing are concentrated in areas with flat terrain and high economic development, such as Yubei and Jiangbei districts. However, these severe vulnerability areas have valley floors, natural slopes, and mountain ridges ranging from $100 \mathrm{~m}$ to nearly $1000 \mathrm{~m}$ in elevation. The GDP of these areas only accounts for $10 \%$ of the Chongqing metropolitan area.

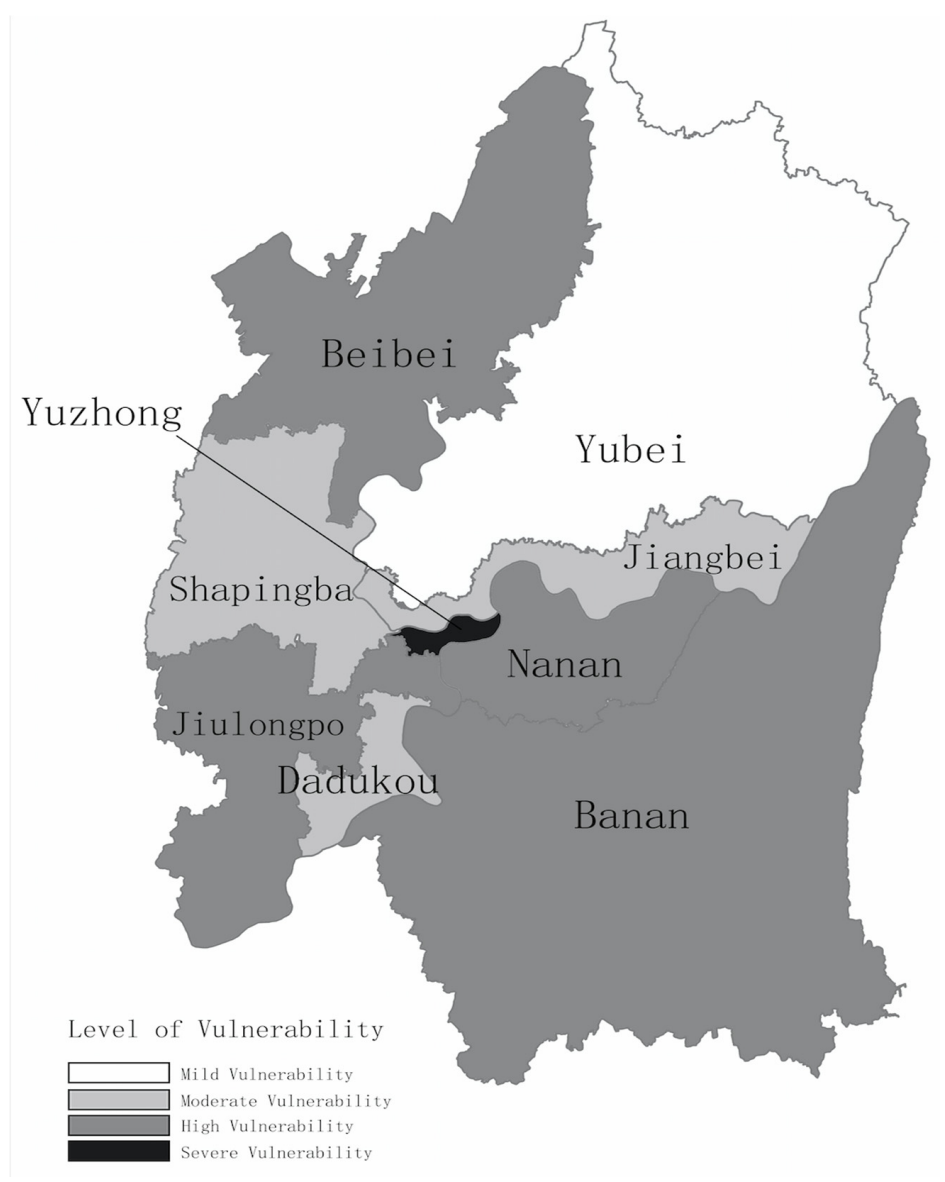

Figure 2. Level of natural disaster vulnerability in Chongqing metropolitan area. 
Yuzhong district, as a mature metropolitan area in Chongqing, has a low risk of natural disasters, but because of its high degree of disaster damage, it is also considered a fragile area. Since the municipalities came under the Chongqing Municipal Government, accompanied by the Chongqing urban regeneration process gradually accelerating, the level of economic development and urbanization rate has greatly improved, and the urban built-up areas have continuously expanded. The urban regeneration is mainly reflected in the following two aspects: first, the development of new urban areas has broadened the scope of the city, such as Yubei, Nanan and Beibei; and, second, to make full use of urban centers, scarce land within cities such as Yuzhong and Jiangbei underwent large-scale demolition and transformation as representatives of the city regeneration movement. However, the urban regeneration of the metropolitan areas in Chongqing is more dominated by historical and cultural protection, rather than taking into account the vulnerability of natural disasters in various regions and the lack of protection for the vital interests of urban residents. In fact, this is a "less inclusive" development model. The current urban regeneration model adopted by Chongqing metropolitan area disrupts the natural balance of regional ecosystem to a certain extent, resulting in a sharp increase in the probability of the occurrence of various natural disasters. In particular, urban green spaces have been seriously eroded, natural vegetation areas have been squeezed, and vegetation coverage decreased which makes areas more prone to floods and other natural disasters. In turn, the proximity to the Yangtze River and Jialing River near Yuzhong, Jiangbei and Nanan and other regions makes urban regeneration more challenging, and thus the process is delayed.

The key areas for current urban regeneration within metropolitan Chongqing are the old urban areas, with specific inherent natural disaster risks. The goals of local government for renovation of these areas are mainly to promote regional economic development, with little consideration of the prevention of regional natural disasters or the protection of indigenous people's property safety. Yuzhong, for example, has practically no new expansion area, and the only options are to update the old urban areas. However, in the process of urban regeneration, the assessment of some regional regeneration is still focused on economic factors, and there is no correct understanding of the serious vulnerability to natural disasters in the region. Yuzhong District's eighteen ladder area for example, is situated at the confluence of the Yangtze and Jialing Rivers, posing significant threat of perennial floods, landslides and other natural disasters. Most of its housing infrastructure, such as power and water supply, communications and other infrastructure, is particularly vulnerable. Due to the impact of economic factors, the progress of urban regeneration is slow and the property and safety of the local aboriginal people is not effectively protected. Jiulongpo, Nanan, Beibei, Banan, Jiangbei and other urban areas face similar problems, with too much emphasis on the development of the urban economy, while ignoring other factors, which is not conducive for the city's long-term sustainable development.

Therefore, the urban regeneration of Chongqing metropolitan area not only needs to consider the social and economic factors, but also needs to focus on assessing the natural disaster vulnerability of the renovation area, with a focus on the main urban regeneration. On the one hand, actively use the advanced concept of NBS, in the activities of urban regeneration in the comprehensive consideration of social, economic and natural environment and other factors, to achieve inclusive urban regeneration. By updating the project plan, the ecological environment, society and economy into a strong life system into the whole process of urban regeneration. It is necessary to establish effective operation mechanism and control mechanism from the aspects of land use, industrial system, environmental capacity, transportation system, cultural style and living environment, and formulate relevant planning, policy guidance, regulatory control, economic support, comprehensive transformation to enhance the inclusion of urban regeneration.

At the same time, while instigating the process of urban regeneration, it is important to respect and protect the natural environment, such as maintaining a regional ecological balance and making efficient use of land for construction. Scarce valleys and flat areas should be devoted to high-density urban development or public open spaces. Particularly vulnerable areas, especially steep alpine slopes, rivers and so on, should have strict prohibition on new urban areas. Urban regeneration activities that 
may directly contribute to natural disasters, such as pollution of river water or clearing of vegetation, should be minimized where possible. Combined with NBS's forward-thinking, attention should be paid to an important part of urban regeneration which is ensuring adequate consideration of the carrying capacity of pollutants, river water, coastal green belts, green parks and other important nodes for ecological transformation.

In addition, it is important to preserve the existing ecosystems that have not been destroyed and increase the urban green areas. Preserving these intact natural ecosystem patches and expanding the urban green areas will help to mitigate the impacts of floods, mudslides and landslides. It is important in the process of urban regeneration, to establish flood control, sand control and other urban disaster prevention infrastructure projects. Decision makers should pay more attention to the protection of regional ecosystems, to avoid large-scale demolition and destruction of the natural environment. Decision makers of natural disaster-prone cities should be sensitive to these special environments and value traditional wisdom that respects natural processes. Over the past decade, Chongqing has further expanded the urbanization to the edge of the nearby mountains, adjacent to steep slopes, and even to the top of the mountain. The rapid urban regeneration process has created constant challenges to traditional wisdom. Local decision makers should be aware that the experience of other cities cannot simply be transferred to these natural disaster-prone cities as there are vastly different natural processes and environmental constraints. This study and its policy implications have important implications for natural disaster-prone cities in China and other developing countries such as Istanbul [41] and Ulaanbaatar's Ger district [42], where attention should be paid to ensure urban regeneration methodology includes protection of the natural environment.

\section{Conclusions}

The vulnerability of cities to natural disasters, particularly in developing countries, including China, has a significant impact on the achievement of sustainable urban regeneration. How to effectively assess the vulnerability of natural disasters in various regions of cities and to use Nature-Based Solutions to help achieve a more sustainable urban regeneration is an important issue for sustainable urban development. However, because all levels of government pay more attention to economic interests in the process of urban regeneration, the development of the whole region is not sustainable. A sustainable urban regeneration that systemically replicates, embeds and integrates the demonstrated nature-based solutions "customized" to their particular context to successfully address the challenges. Actions should address nature-based solutions for inclusive urban regeneration-including regeneration of deprived districts, or neglected or abandoned areas.

Importantly, this paper suggests the use of NBS technology to achieve sustainable urban regeneration and reduce the impact of natural disasters on urban areas. First, this paper defines the concept of urban regeneration and vulnerability of natural disasters, and then analyzes the mechanisms of urban regeneration including vulnerability to natural disasters; taking the Chongqing metropolitan area as an example. The natural disaster vulnerability of nine urban areas within the metropolitan area is quantitatively evaluated according to the DEA model, and the natural disaster vulnerability level of the districts in Chongqing is classified according to the categories of Mild Vulnerability, Moderate Vulnerability, High Vulnerability, and Severe Vulnerability. There are some links between the level of vulnerability, the natural environment and economic development in the urban areas of Chongqing Municipality. According to the natural disaster vulnerability level of each urban area within Chongqing metropolitan area, this paper puts forward the advanced concept of using NBS, and takes a series of effective measures to carry out urban regeneration for each region. Through the implementation of nature-based solutions, healthier, culturally diverse and greener regenerated (including deprived districts and neglected or abandoned areas) cities, making better living conditions for all, increasing green infrastructure and biodiversity, improving air and water quality, enhancing human health and wellbeing, while also increasing awareness of the benefits of re-naturing cities. While these measures 
are effective in understanding how natural disasters impact on urban regeneration, further research is required to fully understand these complex processes.

Acknowledgments: This study is supported by the National Social Science Foundation of China under Grant No. 15BJY038. The work described in this study is also fully supported by a joint grant from Project No. 2017CDJSK03XK19 and No. 106112016CDJSK03JD01 supported by the Fundamental Research Funds for the Central Universities.

Author Contributions: Pengcheng Xiang, Yiming Wang and Qing Deng designed the study; Pengcheng Xiang and Yiming Wang collected and analyzed the data; Yiming Wang wrote the paper; Pengcheng Xiang controlled quality assurance.

Conflicts of Interest: The authors declare no conflict of interest.

\section{References}

1. Ooi, G.L. Challenges of sustainability for Asian urbanisation. Curr. Opin. Environ. Sustain. 2009, 1, $187-191$. [CrossRef]

2. Gong, P.; Liang, S.; Carlton, E.J. Urbanisation and health in China. Lancet 2012, 379, 843-852. [CrossRef]

3. Kaplan, D.H.; Holloway, S. Urban Geography, 3rd ed.; John Wiley \& Sons: New York, NY, USA, 2014; pp. 136-148.

4. Childers, D.L.; Pickett, S.T.A.; Grove, J.M. Advancing urban sustainability theory and action: Challenges and opportunities. Landsc. Urban Plan. 2014, 125, 320-328. [CrossRef]

5. Zhai, B.; Ng, M.K. Urban regeneration and social capital in China: A case study of the Drum Tower Muslim District in Xi'an. Cities 2013, 35, 14-25. [CrossRef]

6. Li, L.H.; Lin, J.; Li, X.L. Redevelopment of urban village in China-A step towards an effective urban policy? A case study of Liede village in Guangzhou. Habitat Int. 2014, 43, 299-308. [CrossRef]

7. Tan, X.; Altrock, U. Struggling for an adaptive strategy? Discourse analysis of urban regeneration processes-A case study of Enning Road in Guangzhou City. Habitat Int. 2016, 56, 245-257. [CrossRef]

8. Simeon, M.I.; Martone, A. Relationships between Heritage, intangible capital and cultural and creative industries in Italy: A framework analysis for urban regeneration and territorial development. Adv. Eng. Forum 2014, 11, 149-156. [CrossRef]

9. Jacobs, J. The Death and Life of Great American Cities; Yilin Press: Nanjing, China, 2014.

10. Hewitt, K. Regions of Risk: A Geographical Introduction to Disasters, 7th ed.; Routledge: London, UK, 2014; pp. 66-78.

11. Gavurova, B.; Siničáková, M. Single Monetary Policy versus Macroeconomic Fundamentals in Slovakia. Ekon. Čas. 2017, 65, 158-172.

12. Birch, K.; Levidow, L.; Papaioannou, T. Sustainable capital? The neoliberalization of nature and knowledge in the European "knowledge-based bio-economy". Sustainability 2010, 2, 2898-2918. [CrossRef]

13. Maes, J.; Jacobs, S. Nature-Based Solutions for Europe's Sustainable Development. Conserv. Lett. 2017, 10, 121-124. [CrossRef]

14. Hong, L.L.; Wang, A. Evaluating the Performance of Public Involvement for Sustainable Urban Regeneration. Procedia Eng. 2016, 145, 1493-1500.

15. Peng, Y.; Lai, Y.; Li, X.; Zhang, X.L. An alternative model for measuring the sustainability of urban regeneration: The way forward. J. Clean. Prod. 2015, 109, 76-83. [CrossRef]

16. Zhai, B.; Ng, M.K. Urban regeneration and its realities in urban China. Urban Plan. Forum 2009, 2, 75-82.

17. Zheng, H.W.; Shen, G.Q.; Wang, H. A review of recent studies on sustainable urban renewal. Habitat Int. 2014, 41, 272-279. [CrossRef]

18. Chen, Z.X. Conclusion of the Principles of Urban Planning and Design-The Machu Picchu Charter. Urban Plan. 1979, 6, 75-84.

19. Wu, L.Y. Beijing Old City and Juer Alley; China Building Industry Press: Beijing, China, 1994; pp. $103-112$.

20. Cheng, D.L.; Zhang, J.X. Urban regeneration: Beyond the material planning action and thinking. City Plan. 2004, 2, 70-73.

21. Zhang, P.Y. Urban regeneration: The trend of urbanization in China in the 21st century. Prog. Geogr. 2004, 4, 72-79.

22. Roberts, P. Evolution, Definition and Purpose of Urban Regeneration; SAGE Publications: London, UK, 2000. 
23. Hausner, V.A. The future of Urban Development. RSA J. 1993, 6, 523-533.

24. Beck, U. The Metamorphosis of the World: How Climate Change Is Transforming Our Concept of the World; John Wiley \& Sons: New York, NY, USA, 2016.

25. International Strategy for Disaster Reduction. Living with Risk: A Global Review of Disaster Reduction Initiatives; United Nations Publications: New York, NY, USA, 2004.

26. Cannon, W.B. Bodily Changes in Pain. Hunger, Fear, and Rage: An Account of Recent Researches into the Function of Emotional Excitement; Appleton and Company: New York, NY, USA, 1915.

27. Wang, Y.; Fang, C.L.; Zhang, Q. Urban Vulnerability Research Review and Prospect. J. Geosci. 2013, 32, 755-768.

28. Crichton, D. The Risk Triangle. In Natural Disaster Management; Tudor Rose: London, UK, 1999.

29. Shi, P.J. Theory and Practice of Disaster Research. J. Nat. Disasters 1996, 5, 6-14.

30. Temmerman, S.; Meire, P.; Bouma, T.J. Ecosystem-based coastal defence in the face of global change. Nature 2013, 504, 79-83. [CrossRef] [PubMed]

31. Fan, P.; Ouyang, Z.; Basnou, C.; Pino, J.; Prak, H.; Chen, J. Nature-based solutions for urban landscapes under post-industrialization and globalization: Barcelona versus Shanghai. Environ. Res. 2017, 156, 272-283. [CrossRef] [PubMed]

32. Liu, Y.; Yue, W.; Fan, P.; Zhang, Z.; Huang, J. Assessing the urban environmental quality of mountainous cities: A case study in Chongqing, China. Ecol. Indic. 2017, 81, 132-145. [CrossRef]

33. Kresta, A.; Tichý, T. Selection of efficient market risk models: Backtesting results evaluation with DEA approach. Comput. Ind. Eng. 2016, 102, 331-339. [CrossRef]

34. Zhou, H.; Hu, H. Sustainability evaluation of railways in China using a two-stage network DEA model with undesirable outputs and shared resources. Sustainability 2017, 9, 150. [CrossRef]

35. Yan, J.; Zhe, L.Z. Research on Natural Disaster Risk Assessment Index System and Method. China Saf. Sci. 2010, 20, 61-65.

36. Global Facility for Disaster Reduction and Recovery (GFDRR). Integrating Disaster Risk Reduction into, the Fight against Poverty: Global Facility for Disaster, Reduction and Recovery-Annual Report 2010; Global Facility for Disaster Reduction and Recovery: Washington, DC, USA, 2010.

37. Zhang, X.; Yi, L.; Zhao, D. Community-based disaster management: A review of progress in China. Nat. Hazards 2013, 65, 2215-2239. [CrossRef]

38. Zhou, Y.; Liu, Y.; Wu, W.; Li, N. Integrated risk assessment of multi-hazards in China. Nat. Hazards 2015, 78, 257-280. [CrossRef]

39. Li, K.; Lin, B. Impact of energy conservation policies on the green productivity in China's manufacturing sector: Evidence from a three-stage DEA model. Appl. Energy 2016, 168, 351-363. [CrossRef]

40. Chongqing Statistics. Available online: www.cqtj.gov.cn (accessed on 13 May 2010).

41. Güzey, Ö. The last round in restructuring the city: Urban regeneration becomes a state policy of disaster prevention in Turkey. Cities 2016, 50, 40-53. [CrossRef]

42. Fan, P.; Chen, J.; John, R. Urbanization and environmental change during the economic transition on the Mongolian Plateau: Hohhot and Ulaanbaatar. Environ. Res. 2016, 144, 96-112. [CrossRef] [PubMed]

(C) 2017 by the authors. Licensee MDPI, Basel, Switzerland. This article is an open access article distributed under the terms and conditions of the Creative Commons Attribution (CC BY) license (http:// creativecommons.org/licenses/by/4.0/). 